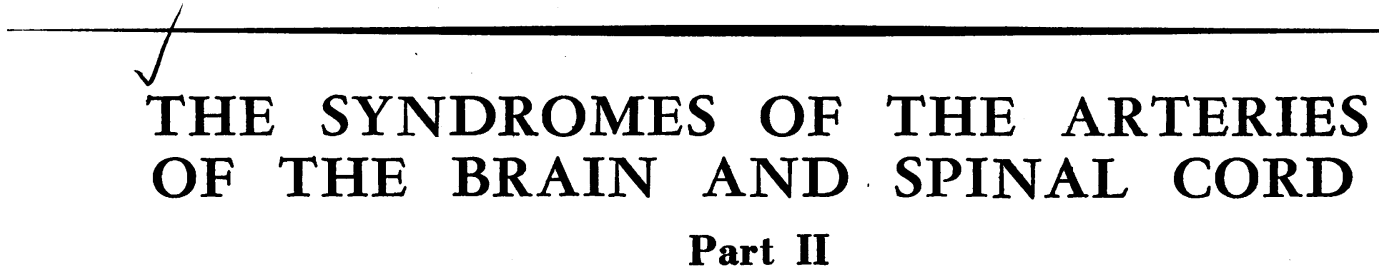

By Leslie G. KILOH, M.D., M.R.C.P., D.P.M.

First Assistant in the Foint Department of Psychological Medicine, Royal Victoria Infirmary and Univer sity of Durham

\section{The Vertebral Artery}

Each vertebral artery enters the foramen magnum in front of the roots of the hypoglossal nerve, inclines forwards and medially to the anterior aspect of the medulla oblongata and unites with its fellow at the lower border of the pons to form the basilar artery.

The posterior inferior cerebellar and the anterior spinal arteries are its principal branches and it sometimes gives off the posterior spinal artery. A few small branches are supplied directly to the medulla oblongata. These are in line below with similar branches of the anterior spinal artery and above with the paramedian branches of the basilar artery.

In some cases of apparently typical thrombosis of the posterior inferior cerebellar artery, post-mortem examination has demonstrated occlusion of the entire vertebral artery (e.g., Diggle and Stcpford, 1935). In some of these the thrombus has extended from the posterior inferior cerebellar artery just before death but in others there is ro doubt that it was the primary condition. In these it is usual to find that the basilar artery has commenced early in the region of the inferior olive and supplies the median area of the medulla oblongata normally irrigated by the vertebral and anterior spinal arteries.

The usual result of vertebral artery thrombosis is simply a combination of those features which result from occlusion of the posterior inferior cerebellar artery and of the medullary portion of the anterior spinal artery with all their variations (q.v.).

Several eponyms have been attached to the syndrome of the vertebral artery. The common picture is sometimes known as the BabinskiNageotte syndrome. The syndrome of CestanChenais is similar but weakness of the tongue and involvement of the descending root of the fifth nerve and of the spinothalamic tract are absent.
(See also Cabot, 1937; Pines and Gilensky, 1930.)

\section{The Posterior Inferior Cerebellar Artery}

The posterior inferior cerebellar artery arises from the vertebral artery at the level of the lower border of the inferior olive and winds round the medulla oblongata between the roots of the hypoglossal nerve. It passes rostrally behind the rootlets of the vagus and glossopharyngeal nerves to the lower border of the pons, bends backwards and caudally along the inferolateral boundary of the fourth ventricle and finally turns laterally into the vallecula.

Branches: From the trunk of the artery, twigs enter the lateral aspect of the medulla oblongata and supply the region bounded ventrally - by the inferior olive and medially by the hypoglossal nucleus-including the nucleus ambiguus, the spinothalamic tract and the restiform body. A branch passes to the chorioid plexus of the fourth ventricle, and in the majority of individuals it also gives off the posterior spinal artery. A twig to the dentate nucleus is present in many individuals (Shellshear, 1922).

The medial terminal branch ramifies over the vermis; the lateral terminal branch supplies the lower surface of the cerebellar hemisphere.

Occlusion of the posterior inferior cerebellar artery gives rise to the lateral medullary or Wallenberg's syndrome. Although credit for the earliest descriptions is usually given to Senator (1883) and Wallenberg (1895), a remarkably detailed and personal account by Gaspard Vieusseux, the Swiss physician, was published by Marcet in I8I 7 .

The clinical picture of posterior inferior cerebellar artery thrombosis shows much variation, though the main features are reasonably constant and diagnostic. 
The onset in a typical case is with intense vertigo, the patient's head and eyes turning to the side of the lesion. He may stagger to the same side and may fall. Nausea and vomiting are almost invariable and the latter may be intractable. Loss of consciousness though not to be expected has been recorded occasionally, as in two of Merritt and Finland's cases (1930). Dysphagia is constant and may even preclude the swallowing of saliva so that a hawking cough develops. Regurgitation of fluids through the nose sometimes occurs although the palatal palsy is strictly unilateral. Speech is commonly affected and in different patients all degrees from hoarseness to aphonia may occur. Less frequently, complaint is made of ipsilateral tinnitus or deafness and diplopia is sometimes troublesome. Hiccough is not infrequent and may persist for days.

Generalized headache or suboccipital pain at the time of onset of the ictus is frequent, but more interesting is the occurrence of facial pain on the same side as the lesion. Rarely is pain in the throat in the distribution of the glossopharyngeal nerve experienced. Complaint is often made of numbness, coldness or of pins and needles over the ipsilateral face and the contralateral body half.

An ipsilateral Horner's syndrome is present in at least 80 per cent. of cases but is frequently incomplete, anhidrosis occurring less commonly than ptosis and miosis. It is due to interruption of the sympathetic connector fibres running from the hypothalamus to the cells of the lateral horn of the grey matter of the cord.

Some weakness of the ipsilateral masticatory and facial muscles may be seen. There may also be loss of taste on the same side over the anterior twothirds of the tongue. Involvement of the ipsilateral sixth nerve is fairly common giving rise to diplopia, but is often so slight that it is difficult to demonstrate clinically. Severe degrees of involvement of the sixth and seventh cranial nerves probably indicate either that the posterior inferior cerebellar artery supplies an unusually wide territory or that short circumferential branches of the basilar artery have been affected coincidentally.

Infarction of the ipsilateral nucleus ambiguus and of its emerging nerve fibres is responsible for the dysphagia, dysarthia and palatal weakness which have already been mentioned. The ipsilateral pharyngeal weakness betrays itself by a ' curtaining' effect of the posterior pharyngeal wall on attempted swallowing and like the ipsilateral palatal weakness is usually severe. The paralysis of the ipsilateral vocal cord may be less marked. The tongue is never affected.

Ipsilateral cerebellar ataxia is present in the great majority of patients. It results mainly from damage to the inferior cerebellar peduncle. Less commonly-because of its rich collateral circula tion-the cerebellum is infarcted and this con-z tributes to the dyssynergia. Nystagmus is usually⿺ gross and there may be skew deviation of the eyes $f_{\text {. }}$ these features are largely attributable to the vestibular disturbance.

The typical sensory changes found are impair은 ment of pain and temperature sensations in the distribution of the ipsilateral fifth nerve and similars impairment over the contralateral body half from $\mathbb{D}$ the second cervical segment downwards. Touch the sense of passive movement and vibration senseare unaffected. The facial changes are due to ischaemia of the descending tract of the fifth nerv $\xi$ which, together with the spinal nucleus of the fifth nerve, underlies the tuberculum cinereumo (The upper part of the spinal nucleus of the fifth. nerve is also affected but in the average case theु lesion of the tract takes precedence.) The contra- $\omega_{\text {}}$ lateral loss of pain and temperature sensations inco the trunk and limbs is due to interruption of the spinothalamic tract which at this level lies internalo to the descending tract and nucleus of the fifth nerve. The opposite side of the face is rarely affected because the quintothalamic tract which arises from the spinal nucleus of the fifth nerven pursues a separate path in the medulla oblongata close to the medial lemniscus and does not join the spinothalamic tract until it reaches the poins (Smyth, 1939). Trophic changes, including ga्ni-0 grene of the side of the nose and adjoining cheeks have been reported, usually associated with the use of a nasal catheter (Savitsky and Elpern, 1948).

Many interesting variants have been noted with regard to the nature and area of the sensory loss Sometimes the ipsilateral face is not involved and? in others only the territory of the first or first and second divisions of the fifth nerve is affected. In the latter the upper parts of the descending tract and spinal nucleus of the fifth nerve escape damage; this provides supporting evidence for the ' upside down' arrangement of this nucleus?. Rarely does ipsilateral impairment of tactilig sensation accompany the loss of pain and temperature sensations.

Occasionally the loss of facial sensation is bilateral, the crossed quintothalamic tract beingo affected as well as the ipsilateral descending root of the fifth nerve. Cases have been noted (Sheehan and Smyth, 1937) in which such contralateral im- N pairment of facial sensation has been restricted ton the area supplied by the ophthalamic division of the fifth nerve. This finding suggests that the quintothalamic tract is laminated, the fibres de rived from the upper face (i.e., from the loweste part of the spinal nucleus) lying on the outside.

Sometimes, owing to the similar lamination of the spinothalamic tract, the contralateral sensoryd 
loss spares the areas supplied by the cervical and even the thoracic segments. The sacral, lumbar, thoracic and cervical fibres lie in this order from without inwards and if the area of infarction does not extend sufficiently far medially, the cervicaland perhaps the thoracic-fibres will escape damage.

The prognosis following occlusion of the posterior inferior cerebellar artery is surprisingly good. The dysphagia, dysarthria and vestibular symptoms commonly disappear and the ataxia shows a marked improvement. The Horner's syndrome and the sensory loss usually persist but occasion little disability.

(See also Anderson et al., r93i ; Goodhart and Davison, 1936; Spillane, r937).

\section{The Anterior Spinal Artery}

Each anterior spinal artery arises near the termination of the vertebral artery and runs obliquely downwards and medially to the anterior aspect of the medulla oblongata, uniting with its fellow opposite the decussation of the pyramids. The combined artery runs downwards in the anteromedian fissure reinforced at intervals by twigs from the vertebral, posterior intercostal and lumbar arteries. Sometimes the two vessels join at once but in other cases they remain independent for several centimetres. Occasionally one is absent.

Twigs from each artery enter the bulb in line with the paramedian branches of the basilar artery and supply the anterior and medial portions of the medulla oblongata, including the pyramidal tract and the medial lemniscus. Stopford (1916, 1917) showed that these vessels also supply the hypoglossal triangle.

Spiller (1908) was the first to describe occlusion of the anterior spinal artery above the level of the decussation of the pyramids. The changes which result constitute the syndrome of the anterior spinal artery of the medulla (paramedian inferior bulbar syndrome).

Double incontinence is frequent at the onset but loss of consciousness is unusual. Contralateral paraesthesiae may be experienced. The most obvious feature is a contralateral hemiplegia affecting the limbs equally but sparing the face. Some contralateral impairment of the sense of passive movement and of vibration sense with astereognosis is usual and is occasionally associated with hyperpathia. Nystagmus is often seen. An ipsilateral 12th nerve paralysis when present is highly characteristic. In its absence, confusion with a lesion of the internal capsule is likely but the escape of the face and the presence of nystagmus will aid distinction.

If the two anterior spinal arteries form a common trunk at a higher level than usual or if one of the contributory arteries is absent, then thrombosis gives rise to a quadriplegia with sensory loss (Louis-Bar, 1947). The resulting picture re- $\frac{\$}{\circ}$ sembles that of basilar artery occlusion but will be distinguished by the absence of 'pseudobulbar' signs.

(See also Davison, I937, 1944; O'Brien and Bender, 1945).

Thrombosis of the inframedullary portion of the anterior spinal artery was first described by $\varnothing$ Preobrajensky (1907).

Thrombosis may occur anywhere in the course $\vec{\circ}$ of the vessel but is most frequent in the cervical $\rightarrow$ region. As it runs downwards the anterior spinal $\vec{\omega}$ artery gives off paired anterior sulcal branches $\frac{5}{0}$ which penetrate the substance of the cord and 0 supply the entire grey matter-with the exception of the tips of the posterior horns-and the greater 6 part of the lateral and anterior funiculi. The supply of these from the posterior spinal arteries is frugal. The latter vessels supply mainly the $\overrightarrow{\overrightarrow{0}}$ posterior columns and the tips of the posterior horns of the grey matter. The anterior sulcal arteries are strictly unilateral in their distribution (Herren and Alexander, 1939).

Pain is common at the onset and is experienced $\stackrel{\supset}{\supset}$ either in girdle distribution at the level of tho $\overrightarrow{0}$ lesion or radiating down the legs. Incontinence $\frac{0}{0}$ o or less commonly retention-of urine and faeces occurs and is sometimes accompanied by priapism? If the artery is occluded in the cervical region there is weakness of all four limbs, initially with flaccidity. In the upper limbs the weakness is largely 'lower motor neurone' in character and is due to segmental destruction of anterior horn cells. Flaccidity will therefore persist and in time wasting will appear. In the lower limbs the weakness is ' upper motor neurone' in type and spasticity usually supervenes. The weakness is commonly asymmetrical. Absence of some or all of the deep reflexes in the upper limbs is associated with the lower motor neurone lesion. The deep reflexes in the lower limbs are often absent in the flaccid stage but become exaggerated if the patient survives. Occlusion in the lumbar region of the cord results in a flaccid weakness of the lower limbs with wasting and loss of deep reflexes.

Sensory loss of a dissociated type is present but is variable in extent. Commonly it affects all segments below the level of the lesion but is often not absolute and may be less marked on one side. Sometimes it is possible to define a zone of absolute loss of pain and temperature sensations in the lower cervical and upper thoracic regions due to destruction of the crossing fibres in the neighbourhood of the central canal, while below this level the sensory loss is incomplete as the spinothalamic tracts re- 


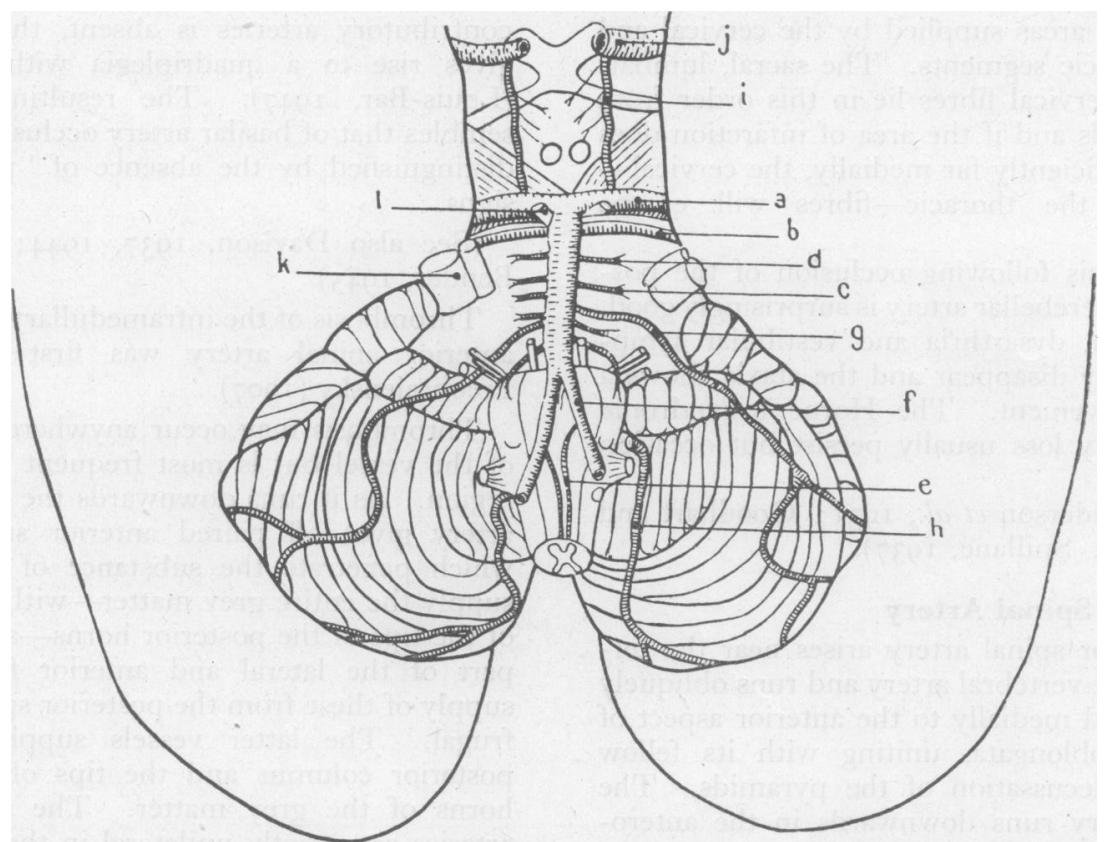

Fig. 4.-The arterial supply of the brain stem and

h Posterior inferior cerebellar artery. cerebellum (semi-diagramatic).

a Posterior cerebral artery.

b Superior cerebellar artery.

c Basilar artery.

d Short circumferential branches of pons.

e Anterior spinal artery.

f Vertebral artery.

g Middle cerebellar artery.

i Posterior communicating artery.

j Internal carotid artery.

$k$ Trigeminal nerve.

1 Oculomotor nerve.

m Pons.

n Lateral artery of medulla oblongata.

(Foix and Hillemand, 1925b.)

ceive some blood from the posterior spinal arteries.

The occurrence of a bilateral Horner's syndrome might be anticipated whenever the lesion is above the level of the first thoracic segment. Curiously enough this appears to have been recorded once only - by Pariser and Lasagna (1949). It may wt:ll be more common than this, for its presence nıay be difficult to establish, especially in ill and perhaps dying patients.

The asymmetry of the condition is sometimes so marked as to merit the title of a Brown-Séquard syndrome (lacking, of course, evidence of ipsilateral posterior column involvement). This may occur during the stage of recovery and when present, suggests that the thrombosis has affected mainly one of the anterior sulcal branches.

In some cases a considerable degree of improvement may take place. More commonly the paralysis remains severe, bed sores and urinary infection develop and the patient suffers the usual fate of any severe chronic spinal affection.

(See also Adams and Merrit, 1944; Steegman, 1952; Sherman, 1948; Zeitlein and Lichtenstein, 1936).

\section{The Basilar Artery}

The basilar artery is formed at the lower border $\stackrel{\mathbb{2}}{2}$ of the pons by the junction of the vertebral $\overrightarrow{\overline{0}}$ arteries. It occupies the basilar groove and ends 3 by dividing into the two posterior cerebral arteries. Its other branches are classified by Foix and Hillemand (1926) into:

(a) Paramedian group (q.v.).

(b) Short circumferential branches (q.v.).

(c) Long circumferential branches: (i) Anterior inferior cerebellar artery (q.v.). (ii) Superior cerebellar artery (q.v.).

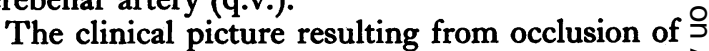
the basilar artery varies widely, as might be ex- $\frac{D}{0}$ pected, according to the precise site and extent of the thrombus. It depends too on the size of the $N$ posterior communicating arteries. If these are $N$ unobstructed and of such a size as to provide an $\mathrm{N}$ adequate collateral circulation, only the territory $\omega$ of those branches blocked by the thrombus will be affected.

At the onset headache may occur and is usually occipital in distribution. 'Dizziness' and, less ? commonly, true vertigo are frequent complaints. Impairment of consciousness varying from slight 


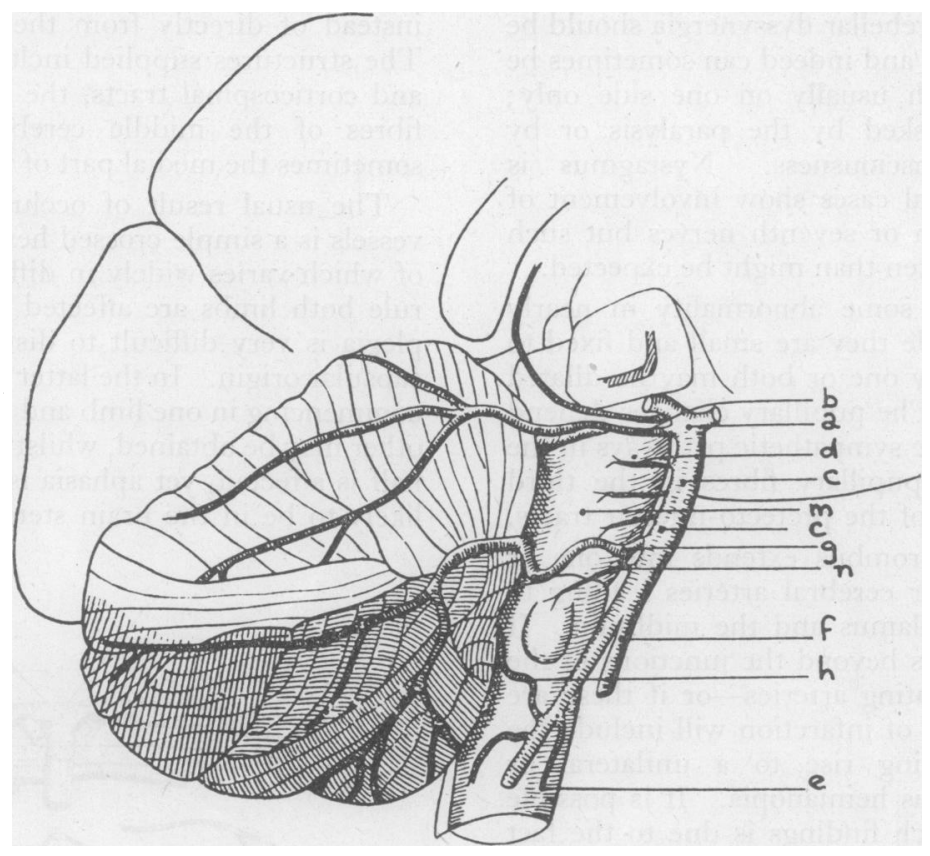

Fig. 5.- The arterial supply of the brain stem and cerebellum-lateral aspect (semi-diagramatic). Key as for Fig. 4. (Foix and Hillemand, 1925b.)

clouding to deep coma is usual. Estimation of the degree of impairment of consciousness may be difficult if the double hemiplegia is so profound as to render impossible any response on the part of the patient. One of Biemond's cases (195I) with a complete anarthria and quadriplegia could move only his eyes to indicate his awareness of the external world. The explanation of the loss of consciousness which occurs so commonly is not altogether clear, for in most of these cases postmortem studies have failed to demonstrate any lesion outside the midbrain and pons. Bremer (1935), from animal experiments, concluded that consciousness ceases when the cerebrum is deprived of afferent stimuli, as would occur in severe midbrain or upper pontine lesions. This view was recently reiterated by Purdon Martin (1949). On the other hand the work of Magoun's school (Lindsley, et al., 1950) suggests that damage to the ascending reticular activating substance is primarily responsible for the alteration in the state of consciousness and Jefferson (1952) has emphasized this possibility in regard to brain stem lesions in man.

Urinary and faecal incontinence is almost invariable even though consciousness be retained. Numbness or tingling down one or other side of the body is common and is most marked in the lips, hands and feet.
Dysarthria, amounting at times to anarthris occurs in most cases and is due to bilateral in terruption of the corticobulbar tracts. Other 'pseudobulbar' phenomena are equally prominent when consciousness is retained sufficiently to allow their demonstration; dysphagia, a spastic tongue which the patient is unable to protrude, bilateral loss of voluntary facial movements and pathological laughing and crying are evident. A double hemiplegia is present in every case but varies greatly in severity. It is frequently asymmetrical and on one side may be indicated by little more than an extensor plantar response. The deep reflexes are usually exaggerated but may be diminished or absent in the acute stage. It might be expected that decerebrate rigidity would be common but this is not so, though it was a prominent feature in Scott and Lennon's case (1940). In Kubik and Adams' (1946) series of 25 cases one only had tonic fits (which may be re- O garded as transient decerebrate states). These $N$ authors suggest that the rarity of the condition N might be due to the existence of a state of ' shock' equivalent to 'spinal shock.'

The supranuclear connections of the eye muscle nuclei are occasionally involved giving rise to defects of lateral or superior conjugate movements. Internuclear ophthalmoplegias occur rarely. 
Theoretically a cerebellar dyssynergia should be present in every case and indeed can sometimes be demonstrated though usually on one side only; commonly it is masked by the paralysis or by impairment of consciousness. Nystagmus is common. Occasional cases show involvement of the third, fifth, sixth or seventh nerves but such signs are seen less often than might be expected.

The pupils show some abnormality in nearly every case. As a rule they are small and fixed to light but occasionally one or both may be dilated and unresponsive. The pupillary changes depend on involvement of the sympathetic pathways in the brain stem, of the pupillary fibres in the third nerves and possibly of the pretecto-nuclear tracts.

Sometimes the thrombus extends into one or both of the posterior cerebral arteries leading to infarction of the thalamus and the midbrain. If the thrombus reaches beyond the junctions of the posterior communicating arteries-or if these are very small-the area of infarction will include the occipital cortex giving rise to a unilateral or bilateral homonymous hemianopia. It is possible that the rarity of such findings is due to the fact that infarction of this severity is almost always fatal.

Tachypnoea, tachycardia and hyperpyrexia are common accompaniments of basilar artery occlusion, though they are usually terminal events.

It is not unlikely that some of the less severe examples of basilar artery occlusion are regarded as cases of pseudobulbar palsy due to bilateral capsular lesions.

The prognosis in basilar artery occlusion is generally considered to be grave, but the fact that of Kubik and Adams' 25 cases seven were still alive after periods varying from two to 14 months, suggests that the outlook is not quite so desperate as was once thought (see also Moniz, 1933; Pines and Gilensky, 1932).

\section{The Paramedian and Short Circumferential Branches of the Basilar Artery}

In general the following description is based on the work of Foix and Hillemand (1926) which appears to be the most accurate assessment of this difficult region.

\section{(A) Paramedian Branches}

There are four to six of these entering the pons a few millimetres on either side of the mid-line. Each divides into numerous branches (sometimes called the median arteries of Düret) running perpendicularly into the substance of the pons. In the uppermost part only do they penetrate into the tegmentum. Sometimes these vessels arise from the short or long circumferential branches instead of directly from the basilar artery itself. The structures supplied include the corticobulbar $\frac{3}{8}$ and corticospinal tracts, the pontine nuclei, some $\cong$

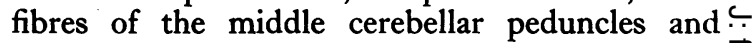
sometimes the medial part of the medial lemniscus. $\overrightarrow{\vec{F}}$

The usual result of occlusion of one of these $\overrightarrow{0}$ vessels is a simple crossed hemiplegia, the severity $\frac{}{\sigma}$ of which varies widely in different patients. As a $\overline{\bar{c}}$ rule both limbs are affected equally. The hemi- $\widehat{\nabla}$ plegia is very difficult to distinguish from one of capsular origin. In the latter a history of weakness $\infty$ commencing in one limb and later extending to the $\vec{\circ}$ other may be obtained, whilst if the dominant body $\overrightarrow{\vec{\omega}}$ half is affected, yet aphasia is absent, the lesion is likely to be in the brain stem. Contralateral im-

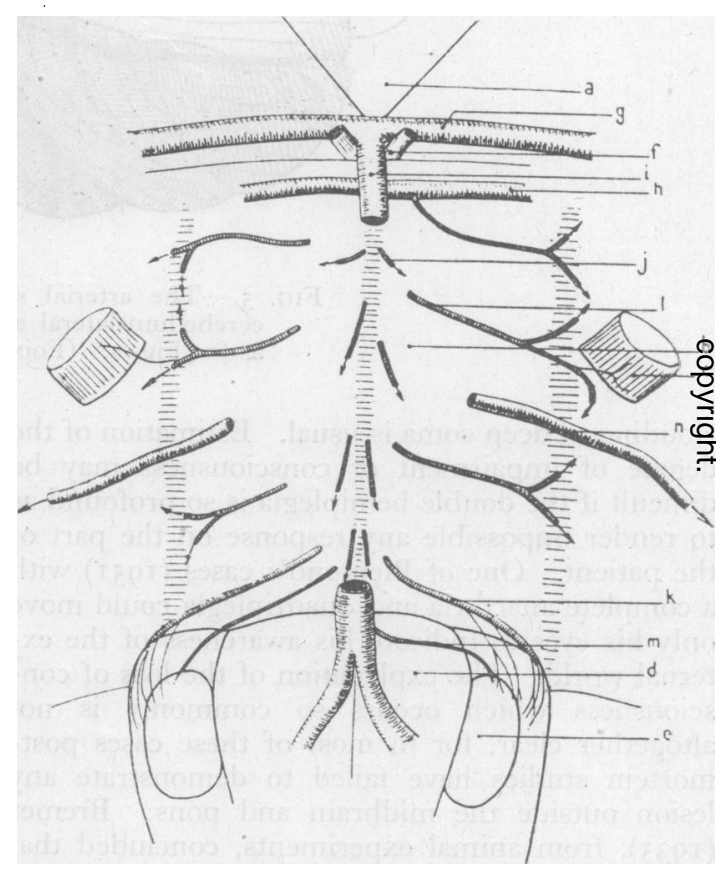

Fig. 6.-Distribution of branches of basilar artery to the brain stem. The basilar artery has been removed. (Diagramatic.)

a Posterior perforated substance.

b Pons.

c Trigeminal nerve.

d. Pyramid.

e Olive.

f Oculomotor nerve.

g Posterior cerebral artery.

$\mathrm{h}$ Superior cerebellar artery.

i Basilar artery.

j Paramedian branches.

$k$ Lateral artery of medulla oblongata.

I Short circumferential branches.

$m$ Accessory lateral artery of the medulla oblongata.

n Middle cerebellar artery.

(Foix and Hillemand, 1925b.) 
pairment of postural sensibility and of vibration sense is stressed by some authors but is only an occasional finding and is rarely severe. Cerebellar signs, which might be anticipated in view of the involvement of the middle cerebellar peduncle, can rarely be demonstrated.

It has been claimed that ipsilateral paralysis of the fifth, sixth and seventh nerves may result from occlusion of the paramedian vessels but this is denied by Foix and Hillemand who say that such features indicate involvement of the short circumferential branches. On anatomical grounds it appears likely that they are correct.

\section{(B) The Short Circumferential Branches}

(i) The lateral artery of the medulla oblongata. This is the lowest lateral branch of the basilar artery. When present it supplies a wedge-shaped area of the lateral aspect of the upper medulla oblongata immediately rostral to that supplied by the posterior inferior cerebellar artery though not including the restiform body (Alexander and Suh, 1937). Foix, Hillemand and Schalit (1925) maintain that occlusion of this vessel gives rise to a syndrome indistinguishable from that following thrombosis of the posterior inferior cerebellar artery and that most of the cases diagnosed as the latter are, in fact, examples of occlusion of the lateral medullary artery. In view of the very large number of cases in which involvement of the posterior inferior cerebellar artery has been proved by post-mortem examination, this view would appear to be exaggerated.

(ii) To the Pons. There are four or five of these and they pass laterally for about one centimetre before entering the pons. A branch of one of them which penetrates the pons with the fifth nerve is sometimes known as the trigeminal artery of Düret. These vessels supply the lateral threefifths of the pons including the lateral portion of the corticospinal tract, the main mass of the medial lemniscus, the trigeminal, abducens and facial nuclei and the middle cerebellar peduncle. With the exception of its uppermost part, these vessels supply the entire tegmentum.

When one or more of these vessels is occluded the result depends very much on whether or not the area of infarction includes the tegmentum.

(a) When it does not, the usual finding is an isolated ipsilateral cerebellar dyssynergia. In some cases this is associated with contralateral sensory loss either affecting all modalities or less commonly pain and temperature sensations alone. A contralateral hemiplegia - slight in degree-may also be present.

(b) When the tegmentum is affected, various cranial nerves, their nuclei and certain adjacent structures may be involved. Although the result- ing syndromes are discussed as clear-cut entities, they also occur in varying combinations:

(I) Millard-Gübler's syndrome. In addition to the long tract involvement of which a contralateral hemiplegia is constant, there is an ipsilateral sixth and seventh nerve paralysis. The latter may be incomplete.

(2) Raymond's syndrome. This is similar to the syndrome of Millard-Gübler but the seventh nerve is not affected.

(3) Foville's syndrome. The essential feature is the presence of paralysis of lateral conjugate ocular movements to the side of the lesion. This is sometimes stated to be due to damage to the parabducens nucleus, but the existence of this body has never been confirmed and it is more likely to result from a lesion of the corticonuclear fibres entering the sixth nerve nuclei. Evidence of long tract involvement is present and there may also be an ipsilateral facial palsy. Foix and Hillemand remark that when due to thrombosis, the hemiplegia seen in these syndromes is never severe. When it is marked it suggests that the causal lesion is a haemorrhage or a neoplasm.

(4) Posterior internuclear ophthalmoplegia. This is associated with damage to the medial longitudinal bundle in the neighbourhood of the sixth nerve nuclei. On looking to the side of the lesiong the ipsilateral eye either fails to deviate outwards or having done so, slowly wanders back towards the neutral position. On looking to the opposite side, the diverging eye may show a similar defect though in lesser degree. In addition, when looking to either side the converging eye may develop coarse lateral jerking movements (ataxic nystagmus). Superficially there is a resemblance to a unilateral or bilateral sixth nerve paralysis but there is no convergent strabismus and the integrity of the sixth nerves can be demonstrated by inducing a vestibular nystagmus.

(5) Bulbopontine syndrome of Düret's trigeminal artery. This syndrome was described by Geréb (1949) and his case appears to be the only one recorded. There was ipsilateral sensory loss restricted to the lower two divisions of the fifth nerve, most evident in the tongue, with loss of taste on the same side and considerable vestibular disturbance.

(6) Palato - pharyngo - laryngeal myoclonus. Rhythmic myoclonic movements of the palate, pharynx and larynx at a rate of 50 to 180 per min. sometimes result from lesions of the pontine tegmentum. The lingual, facial and ocular muscles may also participate in the disturbance. Rarely the diaphragm tos is affected. When due to unilateral vascular disease the myoclonus is also strictly unilateral but is on the opposite side. It results from destruction of the central tegmental 
tract (thalamo-olivary bundle) (Foix and Hillemand, 1926). The ipsilateral inferior olive shows a trans-synaptic degeneration and pseudohypertrophy which is in part due to gliosis (Davison, Riley and Brock, 1936). A lesion of the dentate nucleus is also said to give rise to the same syndrome but in this case the myoclonus is ipsilateral (Guillain, et al., 1933).

Palato-pharyngo- laryngeal myoclonus may occur in isolation but is more commonly accompanied by symptoms of vestibular disturbance and is sometimes combined with a Millard-Gübler or Foville syndrome.

(7) The occurrence of an isolated hemiplegia or of a cerebellar syndrome has already been noted. An isolated spinothalamic lesion giving rise to a dissociated anaesthesia of the entire body half may also occur.

The existence of such discrete features raises the interesting question as to whether or not isolated sixth and seventh nerve palsies (and third nerve paralyses from equivalent lesions of the midbrain) might not have a similar origin. The third and sixth nerve palsies of sudden onset so common in late adult life are usually attributed to small aneurysms or, if none can be demonstrated, to pressure on the nerve by an atheromatous or anomolous vessel. It seems reasonable to suggest that some of these cases are, in fact, the result of brain stem thromboses although no pathological proof of this can be offered.

(See also Alajouanine et al., 1935).

\section{(C) Long Circumferential Branches}

(i) The anterior inferior cerebellar artery (middle cerebellar artery). The anterior inferior cerebellar artery arises from the basilar artery at the junction of its middle and lower thirds and passes laterally and downwards crossing the acoustic nerve.

Branches from the main stem: Internal auditory artery (in the majority of individuals). Small pontine branches supplying the lateral portion of the lower two-thirds of the pons (including the fifth and seventh nerve nuclei and the cochlear nucleus), the middle cerebellar peduncle and sometimes the uppermost part of the medulla oblongata.

Terminal branches: (a) A branch running laterally and downwards along the medial and anterior border of the cerebellar hemisphere. (b) $A$ branch running directly laterally round the upper edge of the flocculus over the surface of the middle cerebellar peduncle and on to the cerebellar hemisphere.

There is considerable variation in the size and therefore of the importance of the anterior inferior cerebellàr artery. As a rule its size is inversely proportional to that of the posterior inferior cerebellar artery.

Dizziness, tinnitus, nausea and vomiting are $\frac{1}{2}$ common at the onset of occlusion of this vessel $c$. but consciousness is usually retained. On the same side as the lesion are found a cerebellar $\stackrel{?}{?}$ dyssynergia with nystagmus, a Horner's syndrome, a lower motor neurone facial weakness and nerve 흠 deafness. Impairment of all forms of sensation $\frac{\bar{\sigma}}{\vec{D}}$ over the ipsilateral face is usually present though $\stackrel{\mathbb{Q}}{\Omega}$ tactile sensibility may be less affected than pain and temperature sensations. The sensory loss is due $\vec{\circ}$ to involvement of the incoming fifth nerve or of its main sensory nucleus. The only contralateral $\vec{\omega}$ abnormal finding is impairment of pain and temperature sensations in the trunk and limbs. 8 Typically this is incomplete because the area of 3 . infarction is sufficiently posterolateral as not to तु involve the entire spinothalamic tract.

A number of cases of occlusion of the anterior $\mathbb{G}$ inferior cerebellar artery following attempted re- $\vec{\overrightarrow{ }}$ moval of acoustic neuromata have been reported by $\vec{\omega}$

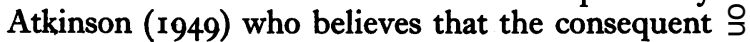
infarction of the tegmental area is responsible for $\overrightarrow{ }$ a transient rise of blood pressure and for the development of cerebral oedema which so commonly leads to death in these patients.

All the features just described as typical $\mathfrak{Q} \overrightarrow{0}$ occlusion of the anterior inferior cerebellar arter may occasionally follow thrombosis of the posterion. inferior cerebellar artery. Involvement of the nucleus ainbiguus never results from disease of the former $v$ ssel and the presence or absence of dysarthria and dysphagia will enable a distinction to be made.

(See also Goodhart and Davison, 1936).

(ii) The superior cerebellar artery. The superior cerebellat arteries are the most constant of the cerebellat vessels. Each arises near the termination of the ba:ilar trunk and runs laterally, parallel to the posterior cerebral artery but separated from it by the third nerve. It turns dorsally round the lateral aspect of the cerebral peduncle to reach the cerebellum.

Branches: Twigs sometimes arise from the main vessel and supply the dorsal aspect of the pons and midbrain. The medial and lateral terminal branches ramify over the superior aspect of the vermis and lateral lobe of the cerebellum and $N$ form the main supply of the cerebellar white matter $N$ and nuclei, including the dentate nucleus. Twigs N also supply the middle and superior cerebellar peduncles, the upper lateral part of the pontine tegmentum, the lateral aspect of the midbrain and the quadrigeminal plate. .

As with occlusion of the other cerebellar arteries, dizziness, vertigo, nausea and vomiting are common at the onset. A cerebellar dyssynergia 
is usually present on the same side as the lesion but may be absent-probably because of the richness of the anastomoses which this artery makes with the other cerebellar vessels. An ipsilateral Horner's syndrome may be seen. The most striking feature is the presence of ipsilateral involuntary movements which may be associated with diminished or absent deep reflexes. The nature of the movements varies from patient to patient and has been described as a coarse tremor by Schuster and Critchley (1933), sinuous movements accentuated by emotion or attempts at voluntary movement by Worster-Drought and Allen (1929), a rapid athetosis by Guillain, Bertrand and Péron (1928) and as chorea by Adams (1943). The movements have been ascribed to involvement of the superior cerebellar peduncle or of the dentate nucleus. Considerable degeneration of the opposite red nucleus with demyelinization of its entering fibres is present in these cases.

Contralateral loss of pain and temperature sensation affects the entire body half including the face but is absent if only the medial branch of the artery is occluded. Sometimes it is confined to the lower part of the body due to the lamination of the spinothalamic tract.
Involvement of cranial nerves or their nuclei is not a feature of superior cerebellar artery occlusion and the partial lesions of the ipsilateral sixth and seventh nerves which have occasionally been described, usually indicate coincidental involvement of the pontine arteries. An ipsilateral fourth nerve paralysis has been described by Girard, $e t$ al (1950).

An occasional feature, notably in the cases described by Mills (1908) and Russel (193I), is loss of emotional movements with preservation of voluntary movements over the contralateral face. This is to be explained as the result of a lesion of the mimic tracts subserving emotional movements which run independently of the pyramidal tracts.

(See also Davison et al., 1935; Freeman and Jaffe, I 941 ; Sandler, 1935.)

\section{Acknowledgments}

We acknowledge with thanks permission to publish illustrations 4,5 and 6 from the Revue Neurolgique and permission to publish illustrations $\mathrm{I}$ and $\mathbf{2}$ from Williams and Wilkins Co., Baltimore.

\section{BIBLIOGRAPHY}

ABBIE, A. A. (1933), ' Clinical significance of the anterior chorioidal artery,' Brain, 56, 233.

ADAMS, R. D. (1943), 'Occlusion of the anterior inferior cerebellar artery,' Arch. Neurol. E' Psychiat., 49, 765.

ADAMS, R. D., and MERRIT, H. H. (I944), 'Meningeal and vascular syphilis of the spinal cord,' Medicine, 23, 181.

AKELAITIS, A. J., RISTEEN, W. A., HERREN, R. Y., and WAGENEN, W. P. (1942), 'Studies on the corpus callosum,' Arch. Neurol. EO Psychiat., 47, 971.

ALAJOUANINE, T., THUREL, R., and HORNET, T. (193.5), 'An anatomoclinical case of palatal and ocular myoclonia, Rev. Neurol., 64, 853 .

ALEXANDER, L., and SUH, T. H. (1937), ' Arterial supply of the lateral parolivary area of the medulla oblongata in man,' Arch. Neurol. \& Psychiat., 38, 1243.

ANDERSON, A. G., LOCKHART, R. D., and SOUTER, W. C. (I931), 'Lateral syndrome of the medulla oblongate,' Brain, 54,560 .

ATKINSON, W. J. (1949), ' The anterior inferior cerebellar artery, F. Neurol. Neurosurg. 'E Psychiat., 12, 137.

BACALOGLU, NICOLESCO, J., RAILEANU, C., and HORNET, T. (1934), 'A propos de la pathologie vasculaire thalamo-mesencéphalique,' Rev. Neurol., $2,896$.

BALDY, R. (1927), 'Les syndromes de l'artère cérébrale antérierue, Paris, Jouve et Cie, cit., Critchley (1930), q.v.

BIEMOND, A. (195I), "Thrombosis of the basilar artery and the vascularization of the brain stem,' Brain, 74, 300.

BREMER, F. (1935), 'Cerveau isolé et physiologie de sommeil,' C.R. Soc. Biol., Paris., 118, 1235.

BROCK, S. J. (1937), 'Basis of Clinical Neurology,' Baltimore, William Wood \& Co.

CABOT, Case 23371 (1937), "Thrombosis of the right vertebral artery,' New England $\}$. Med., 217, 487 .

COGAN, D. G., KUBIK, C. C., SMITH, W. L. (1950), ' Unilateral internuclear ophthalmoplegia,' Arch. Ophth., 44, 783.

CRITCHLEY, M. (1930), "The anterior cerebral artery and its syndromes,' Brain, 53, 120.

DANDY, W. E. (1930), 'Artery of consciousness,' Am. F. Physiol., 93,643 .

DAVISON, C. (1937), ' The syndrome of the anterior spinal artery of the medulla oblongata,' Arch. Neurol. E' Psychiat., 37, 91.

DAVISON, C. (1944), 'Syndrome of the anterior spinal artery of the medulla oblongata,' $\mathcal{F}$. Neuropath. EN Exper. Neurol., 3, 73.
DAVISON, C., GOODHART, S. P., and NEEDLES, W. (1933) 'Cerebral localization in cerebrovascular disease,' Arch. Neurol Es Psychiat., 30, 749.

DAVISON, C., GOODHART, S. P., and SAVITSKY, N. (1935), 'The syndrome of the superior cerebellar artery and its branches,' Ibid., 33, 1443.

DAVISON, C., RILEY, H. A., and BROCK, S. (1936), 'Rhythmic myoclonus of the muscles of palate, larynx and other regions,' Bull. Neurol. Inst., N.Y., 5, 94.

DEJERINE, J., and EGGER, M. (1903), 'Contribution à l'étude de la physiologie pathologique de l'incoordination motrice,' Rev. Neurol., II, 397.

DEJERINE, J., and ROUSSY, G. (Ig06), 'Le syndrome thalamique,'Ibid., 14, $52 \mathrm{x}$.

DIGGLE, F. H., and STOPFORD, J. S. B. (I935), 'Posterior inferior cerebellar and vertebral artery thrombosis,' Lancet, i,1214.

DIMITRI, V., and VICTORIA, M. (1936), ' Syndrome of the anterior cerebral artery,' Revista Neurol., Buenos Ayres, I, 81 .

ELVIDGE, A. R., and WERNER, A. (1951), 'Hemiplegia and thrombosis of the internal carotid system,' Arch. Neurol. E' Psychiat., 66, 752.

ETHELBERG, S. (1951), 'On changes in circulation through the anterior cerebral artery,' Acta. Psychiatra et Neurologica, Supplementum No. 75.

FISHER, M. (r951), 'Occlusion of the internal carotid artery, Arch. Neurol. 'E' Psychiat., 65, 346.

FOIX, Ch., and HILLEMAND, P. (1925a), 'Les syndromes de l'artère cérébrale antérieure,' Encéphale, 20, 209.

FOIX, CH., and HILLEMAND, P. (1925b), 'Les artères de l'axe encéphalique jusqu'au diencéphale inclusivement,' Rev. Neurol., 2, 705 .

FOIX, СH., and HILLEMAND, P. (1926), 'Contribution a l'étude des ramollissements protubérantiels,' Rev. de Médecine, 43, 287.

FOIX, CH., HILLEMAND, P., and SCHALIT (1925), 'Sur e syndrome latéral du bulbe et l'irrigation du bulbe supérieure, Rev. Neurol., $1,160$.

FOIX, CH., and LEVY, M. (1927), 'Softening in the region of the Sylvian artery,' Ibid., 2, $\mathrm{x}$.

FREEMAN, W., and JAFFE, D. (194I), ' Occlusion of the superior cerebellar artery; report of a case with autopsy,' Arch. Neurol. E Psychiat., 46, 115. 
GERÉB, T. (1948), 'Bulbopontile syndrome of Düret's trigeminal artery, Monatschr. f. Psychiat. u. Neurol., II5, 103.

GIRARD, P. F., BONAMOUR, GARDE, and ETIENNE (1950), 'Les syndromes de l'obliteration de l'artère cérébelleuse supérieure,' Rev. Neurol., 83, 199.

GOODHAR'T, S. P., and DAVISON, C. (1936), 'Syndromes of the posterior inferior and anterior inferior cerebellar arteries and their branches,' Arch. Neurol. E' Psychiat., 35, $50 \mathrm{r}$.

GUILLAIN, G., BERTRAND, I., and PERON, N. (1928), ' Le syndrome de l'artère cérébelleuse superieure,' Rev. Neurol., 2, 835 .

GUILLAIN, G., THUREL, R., and BERTRAND, I. (1933) - Examen anatamopathologique d'un cas de myoclonies vélopharyngo-oculo-diaphragmatiques,' Ibid., 2, 801.

HERREN, R. Y., and ALEXANDER, L. (1939), 'Sulcal and intrinsic blood' vessels of the human spinal cord,' Arch. Neurol. E Psychiat., 41, 678.

HYLAND, H. H. (1933), 'Thrombosis of intracranial arteries, Ibid., 30, 342 .

JEFFERSON, M. (1952), 'Altered consciousness associated with brain stem lesions,' Brain, 75, 55.

KUBIK, C. S., and ADAMS, R. D. (1946), ' Occlusion of the basilar artery, Ibid., 69, 73 .

LANGWORTHY, O. R., and FOX, H. M. (r937), "Thalamic syndrome; syndrome of posterior cerebral artery,' Arch. Int. Med., 60, 203 .

LINDSLEY, D. B., SCHREINER, L. H., KNOWLES, W. B. and MAGOUN, H. W. (1950), 'Behavioural and EEG changes following chronic brain stem lesions in the cat,'EEG Clin. Neurophysiol., 2, 483 .

LOUIS-BAR, D. (1947), 'Syndrome of the anterior spinal artery paramedian inferior bulbar syndrome),' Monatschr. f. Psychiat. u. Neurol., 113, 40 .

MARCET, A. (1817), ' History of a singular nervous or paralytic affection attended with anomalous morbid sensations,' MedicoChirurgical Trans., 2, 217.

MAR'TIN, P. (1949), ' Consciousness and its disturbances,' Lancet, i, 1 .

MERRIT'T, H. H., and FINLAND, M. (1930), 'Vascular lesions of the hind brain (lateral medullary syndrome), Brain, 53, 290.

MEYERS, R. SWEENEY, D. B., and SCHWIDDE, J. T. (I950), 'Hemiballismus, aetiology and treatment,' $\mathcal{F}$. Neurol. Neurosurg. Eீ Psychiat., 13, 115.

MILLS, C. K. (1908), 'Hemianaesthesia to pain and temperature and loss of emotional expression of right side with ataxia of upper limb on the left,' $\mathcal{F}$. Nerv. E' Mental Dis., 35, 33r.

MONIZ, E. (r931), 'Hemibalismo, a proposito de tres casos,' Lisbon Medica, 8, $48 \mathrm{I}$.

MONIZ, E. (r933), 'The basilar trunk and arteries derived from it,' Encéphale, 28, 705.

NIELSON, J. M. (1946), 'Agnosia, apraxia and asphaia,' New York, Paul B. Hoeber.

O'BRIEN, F. H., and BENDER, M. B. (1945), 'Localizing value of vertical nystagmus (anterior spinal artery thrombosis),' Arch. Neurol. E' Psychiat., 54, 378

PARISER, S., and LASAGNA, L. (r949), 'Occlusion of the anterior spinal artery,' $\mathcal{F}$. Mt. Sinai Hosp., 16, 128.

PINES, L., and GILENSKY, E. (1930), ' Thrombosis of vertebral artery,' Arch. f. Psychiat., 90, 177.
PINES, L., and GILENSKY, E. (1932), 'Thrombosis of basilar artery and vascularization of pons varolii,' Ibid., 97, 380 .

POPPEN, J. L. (1939), 'Ligation of the anterior cerebral artery,' Arch. Neurol. E' Psychiat., 4I, 495.

PREOBRAJENSKY (1907), 'Thrombosis of anterior spinal artery,' cit., Zeitlin and Lichtenstein (1936), q.v.

RUBINSTEIN, H. S. (1944), 'The anterior communicating artery in man,' F. Neuropath. E' Exp. Path., 3, 196.

RUSSEL, C. K. (193I), 'Syndrome of the brachium conjunctivum? and tractus spinothalmicus,' Arch. Neurol. 'E Psychiat., 25, 1003 .

SANDLER, S. A. (1935), 'Syndrome of superior cerebellar artery,' F. Nerv. Eं Mental Dis., 82, 263.

SAVITSKY, N., and ELPERN, S. P. (1948), 'Gangrene of face $\overparen{\mathbb{Q}}$ following occlusion of posterior inferior cerebellar artery, 0 Arch. Int. Med., 84, 431.

SCHALLER, W. F., ROBERTS, A. M., and STADTHERR, E. F. (I932), 'Acute myelitis (syndrome of occlusion of anterior $\vec{O}$ spinal artery), ' F.A.M.A., 99, 1572.

SCHUSTER, P., and CRITCHLEY, M. (1933), 'Beiträge zur Anatomie und Pathologie der Arteria cerebelli superior,' $\omega$ Ztschr. f.d. ges Neurol. u. Psychiat., 144, 681.

SCOTT, M., and LENNON, H. C. (I940), 'Decerebrate tonic extensor convulsions as a sign of occlusion of the basilar artery, Arch. Neurol. E' Psychiat., 44, 1102.

SENATOR, H. (1883), ' Zur diagnostik der Herderkrankungen inī der Brücke under der verlängerten Mark,' Arch. f. Psychiat., 14,643 .

SHEEHAN, C., and SMYTH, G. E. (1937), 'A study of the N anatomy of vertebral thrombosis,' Lancet, ii, 614 .

SHELLSHEAR, J. L. (1922), ' Blood supply of the dentate nucle us of the cerebellum, Ihid., i, 1046. SHERMAN, I. C. (I 948$), '$ Thrombosis of anterior spinal artery,'O
Arch. Neurol. EO Psychiat., 59, 844.

SMYTH, G. E. (1939), 'The systematization and central connectionsof the spinal tract and nucleus of the trigeminal nerve,' Brain, $>$ 62, 4I.

SPILLANE, J. D. (1937), 'Posterior inferior cerebellar arteri. thrombosis,' Bull. Neurol. Inst. New York, 6, 529.

SPILLER, W. G. (1908), " The symptom complex of a lesion of the uppermost portion of the anterior spinal and adjoining portonce of the vertebral arteries,' $\mathcal{f}$. Nerv. E' Mental Dis., 35, 7750

STEEGMAN, A. T., and ROBERTS, D. J. (1935), ' Syndromefof anterior chorioidal artery,' $\mathcal{Y}$. A.M.A., r04, 1695 .

STOPFORD, J. S. B. (1916, 1917), The arteries of the pons medulla oblongata. F. Anat. E' Physiol., 50, 131, 255; $51,252 \leq$

TICHY, F. (1949), 'Syndromes of cerebral arteries,' Arch. 'Path 48, 475 .

WALLENBERG; A. (1895) 'Acute Bulbäraffection (Embolie der̃ Art. Cerebellar post. inf. sinistr.?),' Arch. f. Psychiat., 27, 504.\$

WILLIAMS, D. J. (1936), ' Origin of the posterior cerebral artery, Brain, 59, 175 .

WORSTER-DROUGHT, C., and ALLEN, I. M. (1929), ' Thrombosis of superior cerebellar artery,' Lancet, ii, 1137 .

ZEITLEIN, H., and LICHENSTEIN, B. W. (1936) ' Occlusion of the anterior spinal artery,' Arch. Neurol. E尺 Psychiat., 36, 96.

\section{H. K. LEWIS \& Co. Ltd. Medical Publishers and Booksellers}

Catalogues on request State interests

\section{GOWER STREET LONDON, W.C. 1}

(Adjoining University College and Hospital)

Telephone: EUSton 4282 (7 lines)

Telegrams: Publicavit, Westcent, London

Business hours: 9 a.m. to 5 p.m. Saturdays: 1 p.m.

\section{Medical Lending Library}

ANNUAL SUBSCRIPTION frOm TWENTY-FIVE SHILLINGS

For the CONVENIENCE of POST-GRADUATE STUDENTS SHORT PERIOD SUBSCRIPTIONS ARE ARRANGED - for 3 or 6 month

Detailed Prospectus on application

The Library Catalogue revised to December, 1949, containing classified index of authors and subjects

To subscribers $17 / 6$ net; To non-subscribers $35 /-$ net. Postage $1 / 3$

Supplement 1950-1952 in preparation

Bi-Monthly List of New Books and New Editions

sent post free on request

NEW BOOKS ADDED IMMEDIATELY UPON PUBLICATION 